\title{
Foot Involvement as the First Manifestation in Rheumatoid Arthritis Patients in Lahore
}

\author{
Sajid Ali Khan ${ }^{1}$, Muhammad Ahmad Saeed ${ }^{1}$, Sumaira Farman ${ }^{1}$, Zarghoonah Sajid ${ }^{2}$, Nighat Ahmad ${ }^{1}$, \\ Masood Alam ${ }^{3}$ \\ 1. Rheumatology, Fatima Memorial Hospital College of Medicine and Dentistry, Lahore, PAK 2. Medicine, Mian \\ Muhammad Shahbaz Sharif Hospital, Lahore, PAK 3. Pulmonology, Chaudhary Pervaiz Elahi Institute of Cardiology, \\ Multan, PAK
}

Corresponding author: Sajid Ali Khan, sajid_2456@yahoo.com

\section{Abstract \\ Objective}

The objective of this study was to determine the involvement of the foot as the first manifestation in rheumatoid arthritis (RA).

\section{Methods}

This study was conducted on 100 patients who presented to the outpatient department of the Rheumatology Department at Fatima Memorial Hospital and College of Medicine and Dentistry in Lahore, Pakistan. The period of this cross-sectional study was three months - from October 2017 to December 2017. One hundred patients aged more than 16 years, who were diagnosed as cases of RA with foot involvement, and with a disease duration of less than two years (to minimize recall bias), were enrolled for the study.

\section{Results}

Out of the 100 patients, $20 \%$ were male and $80 \%$ were female. The mean age of the study population was $41.16 \pm 12.343$ years. Foot Involvement as the first manifestation was noted in 29 (29\%) of the cases. The pattern of foot involvement shows a 59\% forefoot involvement, $27 \%$ hindfoot involvement, and $14 \%$ midfoot involvement. Walking difficulty was most common in forefoot involvement (71.42\% of cases), followed by hindfoot involvement ( $20 \%$ of cases), and least common in midfoot involvement ( $8.57 \%$ of cases) $(\mathrm{p}=0.0001)$.

\section{Conclusion}

Foot involvement as the first manifestation is quite common in RA and should not be ignored, especially in patients with large joint involvement sparing the hands.

Review began 05/17/2021 Review ended 05/26/2021 Published 05/31/2021

(c) Copyright 2021 Ali Khan et al. This is an open access article distributed under the terms of the Creative Commons Attribution License CC-BY 4.0., which permits unrestricted use, distribution, and reproduction in any medium, provided the original author and source are credited.
Categories: Rheumatology

Keywords: foot involvement, rheumatoid arthritis, walking difficulty, ra factor, anti ccp antibodies

\section{Introduction}

Rheumatoid arthritis (RA) is the prototypical multisystem autoimmune disorder with a broad spectrum of joint presentations encompassing almost all joints and soft tissues. It has a $39 \%$ morbidity within 10 years of onset [1]. It is a disease that affects multiple joints, with the small joints of the wrist, hands, and feet being the most commonly affected joints [2]. RA is a disease of unknown etiology [3]. Its presentation and course are highly variable and range from minimal to fulminant [4].

Overall, in the population of the world, without any differences between developed and developing countries, rheumatoid arthritis affects $0.5-1.9 \%$ of people $[5,6]$. In Pakistan, the prevalence of RA is reported to be $0.142 \%$ in the southern regions [7] and $0.55 \%$ in the northern areas [8].

Persons with sensitivity to two HLA-DRB1 alleles are at more risk of developing RA than those who have a single-dose genotype [9]. A study conducted by Yahya A et al. in the Malaysian population reported that anti-citrullinated protein antibody (ACPA)-positive RA was observed in persons in the silica profession. Smokers exposed to silica dust are at a high risk of developing ACPA-positive RA [10].

Infections, as associated with other autoimmune disorders, have been extensively studied in RA. Although there is still no pathogen-derived antigen clearly linked to RA pathogenesis, the link between the human microbiome (particularly in the gut, oral cavity, and lungs) and the host's immune system is being intensively investigated. A change from a normal symbiotic relation to a "dysbiotic" microbiome is thought to be responsible for changes in both innate as well as the adaptive arm of immunity. This could be a factor in the development of RA [11]. 
The main types of arthritis cannot be differentiated on the basis of histology or the characteristics of cellular infiltrates. Therefore, a biopsy of the synovial tissue is rarely used as a diagnostic tool [12].

After the development of higher sensitivity criteria of 2010 American College of Rheumatology/European League Against Rheumatism (ACR/EULAR), a significant burden of the patients who were previously regarded as undifferentiated arthritis were categorized as rheumatoid arthritis [13]. The newly emerging criteria comprise the majority of clinically related parameters that were included in Leiden prediction rules. Their successful use helps discriminate between patients with high risk and those with low risk in terms of the radiological progression of the disease. In another trial called IMPROVED study, undifferentiated arthritis patients who did not fulfil the 2010 criteria were found to be less active, had lower tender joint count (TJC) and swollen joint count (SJC), and showed significantly lower proportions of ACPA and rheumatoid factor (RF) positive rates in comparison to RA (ACPA: 3\% compared with 68\%; RF: $4 \%$ versus $69 \%$ ), as well as better prognostic features in terms of radiographic progression [14].

The strategy of treatment is always based on the "treat to target" approach. In this approach, one to three months of follow-up of the patient is required with proper treatment until the goal is achieved. Ten important recommendations were developed by the international task force of RA experts to educate patients and to guide practitioners in planning for better outcomes [15].

The prevalence of bacterial infection is very high in patients with RA due to the use of immunosuppressive (glucocorticoids) disease-modifying antirheumatic drugs (DMARDs) and biological agents. Through study results, we know that anti-tumour necrosis factor (TNF) therapy can double the risk of a serious infection [16].

Patients with RA are at risk of malignancy, like lymphoma in many patient subsets, especially with seropositive patients and those with longstanding disease. These patients have been advised that they are at risk of the severity and inflammatory activity of the disease. The anti-TNF drugs do not enhance the rate of malignancy, except in skin cancers, including melanoma and non-melanoma [17].

Approximately $13 \%$ of patients have foot involvement as the first sign of RA, and $90 \%$ of patients will have foot manifestations at some point during the course of the disease [18]. Foot involvement has been found to be the most common reason for disability in patients with RA, with the forefoot being the most common area [19]. According to a study conducted in 2012, at the site of the foot, the symptoms are mostly in the ankle (36\%) and forefoot (30\%), followed by the hindfoot (17\%) and midfoot (7\%) [20]. The deformities caused by foot involvement in RA include hallux valgus (HV), dorsal dislocation of the metatarsophalangeal (MTP) joints, and hammertoe deformity of the lesser toes. Changes to the forefoot that are found commonly in these patients include bunions, claw toes, "cock-up" deformity of the small toe, and pain affecting the ball of the foot. In some cases, the heel may also become painful. Despite the foot being a common cause of pain and disability, it is often overlooked in the clinical assessment of RA [16]. Foot involvement causes walking disability in three-quarters of the cases, which is four times as often as the hip or knee joint $[18,19]$.

The new RA classification criteria were set as part of a joint ACR/EULAR effort in 2010 [20]. In these criteria, the small joints are given the maximum weightage, which is why foot involvement (having 33 small joints) as the first manifestation in RA should not be ignored. The purpose of this study is to enhance the sensitivity of the ACR criteria in making early diagnosis of RA in patients with the involvement of predominately large joints, sparing the hands but having foot involvement.

\section{Materials And Methods}

This was a prospective, cross-sectional analysis of 100 outpatients in the Department of Rheumatology, Fatima Memorial Hospital (FMH), which is a tertiary care hospital in Lahore city of Pakistan. All patients fulfilling the ACR/EULAR 2010 diagnostic criteria with foot involvement and having a disease duration of less than two years were enrolled in the study over a period of three months. All patients with degenerative diseases and anatomical abnormalities were excluded. The study was approved by the institutional review board of FMH. Informed consent was obtained from all subjects according to the 2008 Declaration of Helsinki.

The detailed history and clinical examination of the patients were recorded. Demographic data, such as age, gender, and area of residence, were noted on a form. The patients were asked to point out the first involved area of the body due to the disease. Every patient was asked to point out the area of foot involvement on homunculus divided into forefoot, midfoot, and hindfoot. The patients were asked if they had any difficulty walking. The status of RA factor and anti-cyclic citrullinated peptide (CCP) antibodies was recorded from their medical records.

All data was entered and analyzed in SPSS Statistics version 21 (IBM Corp., Armonk, USA). The quantitative variables were presented as mean and standard deviation. Frequencies and percentages were analyzed for the qualitative variables. A p-value of $\leqslant 0.05$ was considered significant. 


\section{Cureus}

\section{Results}

One hundred patients were enrolled in the study; $n=20$ (20\%) were male and $n=80$ (80\%) were female. The mean age of the study population was $41.16 \pm 12.34$ years. Foot Involvement as the first manifestation was noted in $n=29$ (29\%) cases. RA factor was positive in $n=58(58 \%)$ cases. Anti-CCP antibodies were positive in $n=63$ (63\%) cases. The pattern of foot involvement showed $n=59$ (59\%) cases of forefoot involvement, $n=27$ (27\%) cases of hindfoot involvement, and $n=14$ (14\%) cases of midfoot involvement (Table 1). Walking difficulty was most common in forefoot involvement (71.42\% of cases), followed by hindfoot involvement ( $20 \%$ of cases), and the least common in midfoot involvement ( $8.57 \%$ of cases) ( $p=0.0001$ ) (Table 2 ). Walking difficulty was significantly associated with the pattern of foot involvement, with the forefoot being the most commonly involved in walking difficulty ( $\mathrm{p}=0.019$ and 0.0001 , respectively) (Tables 2, 3).

\begin{tabular}{|c|c|c|}
\hline Variable & Frequency & Percentage \\
\hline \multicolumn{3}{|l|}{ Gender } \\
\hline Male & 20 & $20.0 \%$ \\
\hline Female & 80 & $80.0 \%$ \\
\hline Foot involvement as the first manifestation & 29 & $29.0 \%$ \\
\hline RA factor & 58 & $58.0 \%$ \\
\hline Anti-CCP antibodies & 63 & $63.0 \%$ \\
\hline \multicolumn{3}{|l|}{ Pattern of foot involvement in RA } \\
\hline Forefoot involvement & 59 & $59.0 \%$ \\
\hline Hindfoot involvement & 27 & $27 \%$ \\
\hline Involvement of midfoot & 14 & $14 \%$ \\
\hline
\end{tabular}

TABLE 1: Demographic characteristics of the patients

RA: rheumatoid arthritis; CCP: cyclic citrullinated peptides

\begin{tabular}{|c|c|c|c|}
\hline \multirow{2}{*}{ Pattern of Foot Involvement } & \multicolumn{2}{|c|}{ Walking Difficulty } & \multirow{2}{*}{ Total } \\
\hline & Yes & No & \\
\hline Forefoot & 50 & 9 & 59 \\
\hline Midfoot & 6 & 8 & 14 \\
\hline Hindfoot & 14 & 13 & 27 \\
\hline Total & 70 & 30 & 100 \\
\hline Chi-square & 15.225 & & \\
\hline P-value & 0.0001 & & \\
\hline
\end{tabular}

TABLE 2: Association between the pattern of foot involvement and walking difficulty 


\section{Cureus}

\begin{tabular}{|c|c|c|c|}
\hline \multirow{2}{*}{ Foot Involvement as First Manifestation } & \multicolumn{2}{|c|}{ Walking Difficulty } & \multirow{2}{*}{ Total } \\
\hline & Yes & No & \\
\hline Yes & 25 & 4 & 29 \\
\hline No & 45 & 26 & 71 \\
\hline Total & 70 & 30 & 100 \\
\hline Chi-square & \multicolumn{3}{|l|}{5.109} \\
\hline P-value & \multicolumn{3}{|l|}{0.019} \\
\hline
\end{tabular}

TABLE 3: Stratification of foot involvement as the first manifestation with respect to walking difficulty

\section{Discussion}

There are no prior studies on foot involvement in RA in Pakistan. Although RA has been extensively studied, the foot has remained an understudied manifestation of rheumatoid arthritis, resulting in a higher proportion of missed diagnosis, especially in patients with large joint involvement sparing the hands.

This was a small-scale study to determine foot involvement in rheumatoid arthritis as the first manifestation. It showed that the foot is involved as the first manifestation in $29 \%$ of cases, which makes it a significant diagnostic consideration. The forefoot is the most commonly involved part of the foot and is also the most common cause of walking difficulty. Foot involvement is independent of the seropositive or seronegative status of the patient.

In one study by Grondal et al., the forefoot was involved in $45 \%$ of the patients, and the hindfoot/ankle was involved in $17 \%$ [21]. This supports our study which shows a $59 \%$ involvement of the forefoot. Difficulty in walking due to the feet was reported by $71 \%$ of the patients, which is almost the same as our study. For $41 \%$ of the patients, the foot was the most important part of the lower extremity that was causing reduced walking capacity - this is also similar to our study.

In a study by Keenan et al., it was demonstrated that the midfoot and ankle are the least commonly involved joints of the foot in RA [22]. This result also supports the results of our study.

Concerning RA, forefoot joint damage was significantly correlated with forefoot pressure [23], and RA patients showed lower medial and higher lateral forefoot peak pressures compared to healthy controls [24]. This explains the increased involvement of the forefoot and the higher incidence of walking difficulty with forefoot involvement that was observed in our study.

In a study by Michelson J et al., 93 out of 99 patients had complaints related to the foot or ankle at some time since their diagnosis of RA. Ankle problems were paramount in $42 \%$, forefoot difficulties in $28 \%$ of patients, and $14 \%$ of the patients had equal ankle and forefoot problems [25]. These findings are in contrast to our observations, in which the forefoot is the most commonly involved part. Michelson et al. also concluded that their findings were opposite to other studies which indicate a more common involvement of forefoot. The reason for this discrepancy has not been discussed in the study.

In one study conducted in Singapore, Carter K et al. studied the prevalence of foot problems in people with inflammatory arthritis. They found that the foot is involved in $45 \%$ of cases in people with RA. However, no comment was made on the pattern of foot involvement or the walking difficulty caused by it [26].

No local data is available on this subject in Pakistan or its neighbouring countries.

This is a small-scale study and needs further validation on a larger scale. However, it gives us a good insight into the pattern of foot involvement in rheumatoid arthritis on which future studies can be based.

\section{Conclusions}

In this study, foot involvement as the first manifestation was seen in about one-third of the patients. This study suggests that clinicians taking care of patients with early inflammatory arthritis should perform a focused examination of the feet to look for synovitis involving the small joints of the feet. This may increase the sensitivity of the new ACR/EULAR criteria, especially in the patients in whom the small joints of hands are spared at the outset of the disease. 


\section{Additional Information \\ Disclosures}

Human subjects: Consent was obtained or waived by all participants in this study. Fatima Memorial Hospital Institutional Review Board issued approval FMH-10-2017-IRB-309-M. Foot involvement as first manifestation in rheumatoid arthritis patients in Lahore is approved from the ethical committee. Animal subjects: All authors have confirmed that this study did not involve animal subjects or tissue. Conflicts of interest: In compliance with the ICMJE uniform disclosure form, all authors declare the following: Payment/services info: All authors have declared that no financial support was received from any organization for the submitted work. Financial relationships: All authors have declared that they have no financial relationships at present or within the previous three years with any organizations that might have an interest in the submitted work. Other relationships: All authors have declared that there are no other relationships or activities that could appear to have influenced the submitted work.

\section{References}

1. Eberhardt K, Larsson BM, Nived K, Lindqvist E: Work disability in rheumatoid arthritis--development over 15 years and evaluation of predictive factors over time. J Rheumatol. 2007, 34:481-7.

2. Terao C, Hashimoto M, Yamamoto K, et al.: Three groups in the 28 joints for rheumatoid arthritis synovitis-analysis using more than 17,000 assessments in the KURAMA database. PLoS One. 2013, 8:e59341. 10.1371/journal.pone.0059341

3. Wong SH, Lord JM: Factors underlying chronic inflammation in rheumatoid arthritis . Arch Immunol Ther Exp (Warsz). 2004, 52:379-88.

4. Firestein GS: Etiology and pathogenesis of rheumatoid arthritis . Kelly's Textbook of Rheumatology, 6th Edition. Ruddy S, Harris E, Sledge C (ed): WB Saunders, Philadelphia; 2001. 921-66.

5. Lawrence RC, Helmick CG, Arnett FC, et al.: Estimates of the prevalence of arthritis and selected musculoskeletal disorders in the United States. Arthritis Rheum. 1998, 41:778-99. 10.1002/15290131(199805)41:5<778::AID-ART4>3.0.CO;2-V

6. Hochberg M, Silman A, Smolen J, Weinblatt M, Weisman M: Rheumatoid Arthritis. Mosby Elsevier, St Louis; 2001.

7. Hameed K, Gibson T, Kadir M, Sultana S, Fatima Z, Syed A: The prevalence of rheumatoid arthritis in affluent and poor urban communities of Pakistan. Br J Rheumatol. 1995, 34:252-6. 10.1093/rheumatology/34.3.252

8. Farooqi A, Gibson T: Prevalence of the major rheumatic disorders in the adult population of north Pakistan . Br J Rheumatol. 1998, 37:491-5. 10.1093/rheumatology/37.5.491

9. Balandraud N, Picard C, Reviron D, et al.: HLA-DRB1 genotypes and the risk of developing anti citrullinated protein antibody (ACPA) positive rheumatoid arthritis. PLoS One. 2013, 8:e64108. 10.1371/journal.pone.0064108

10. Yahya A, Bengtsson C, Larsson P, et al.: Silica exposure is associated with an increased risk of developing ACPA-positive rheumatoid arthritis in an Asian population: evidence from the Malaysian MyEIRA casecontrol study. Mod Rheumatol. 2014, 24:271-4. 10.3109/14397595.2013.854076

11. Sandhya P, Danda D, Sharma D, Scaria V: Does the buck stop with the bugs?: an overview of microbial dysbiosis in rheumatoid arthritis. Int J Rheum Dis. 2016, 19:8-20. 10.1111/1756-185X.12728

12. van de Sande MG, Baeten DL: Immunopathology of synovitis: from histology to molecular pathways . Rheumatology (Oxford). 2016, 55:599-606. 10.1093/rheumatology/kev330

13. Chansakul T, Dellaripa PF, Doyle TJ, Madan R: Intra-thoracic rheumatoid arthritis: imaging spectrum of typical findings and treatment related complications. Eur J Radiol. 2015, 84:1981-91. 10.1016/j.ejrad.2015.07.008

14. Mueller RB, Schiff M, Kaegi T, Finckh A, Haile SR, Schulze-Koops H, von Kempis J: The new 2010 ACR/EULAR criteria as predictor of clinical and radiographic response in patients with early arthritis. Clin Rheumatol. 2015, 34:51-9. 10.1007/s10067-014-2737-5

15. Smolen JS, Breedveld FC, Burmester GR, et al.: Treating rheumatoid arthritis to target: 2014 update of the recommendations of an international task force. Ann Rheum Dis. 2016, 75:3-15. 10.1136/annrheumdis2015-207524

16. van Dartel SA, Fransen J, Kievit W, et al.: Predictors for the 5-year risk of serious infections in patients with rheumatoid arthritis treated with anti-tumour necrosis factor therapy: a cohort study in the Dutch Rheumatoid Arthritis Monitoring (DREAM) registry. Rheumatology (Oxford). 2013, 52:1052-7. 10.1093/rheumatology/kes413

17. Raaschou P, Simard JF, Holmqvist M, Askling J: Rheumatoid arthritis, anti-tumour necrosis factor therapy, and risk of malignant melanoma: nationwide population based prospective cohort study from Sweden. BMJ. 2013, 346:f1939. 10.1136/bmj.f1939

18. Posalski J, Weisman MH: Articular and periarticular manifestations of established rheumatoid arthritis . Rheumatoid Arthritis. Hochberg MC, Silman AJ, Smolen JS, Weinblatt ME, Weisman MH (ed): Mosby Elsevier, Philadelphia; 2009. 49-61. https://www.elsevier.com/books/rheumatoid-arthritis/hochberg/978-0323-05475-1

19. Brooks F, Hariharan K: The rheumatoid forefoot. Curr Rev Musculoskelet Med. 2013, 6:320-7. 10.1007/s12178-013-9178-7

20. Aletaha D, Neogi T, Silman AJ, et al.: 2010 rheumatoid arthritis classification criteria: an American College of Rheumatology/European League Against Rheumatism collaborative initiative. Ann Rheum Dis. 2010, 69:1580-8. 10.1136/ard.2010.138461

21. Grondal L, Tengstrand B, Nordmark B, Wretenberg P, Stark A: The foot: still the most important reason for walking incapacity in rheumatoid arthritis: distribution of symptomatic joints in 1,000 RA patients. Acta Orthop. 2008, 79:257-61. 10.1080/17453670710015067 


\section{Cureus}

22. Keenan MA, Peabody TD, Gronley JK, Perry J: Valgus deformities of the feet and characteristics of gait in patients who have rheumatoid arthritis. J Bone Joint Surg Am. 1991, 73:237-47.

23. Tuna H, Birtane M, Taştekin N, Kokino S: Pedobarography and its relation to radiologic erosion scores in rheumatoid arthritis. Rheumatol Int. 2005, 26:42-7. 10.1007/s00296-004-0504-7

24. van der Leeden M, Steultjens M, Dekker JH, Prins AP, Dekker J: Forefoot joint damage, pain and disability in rheumatoid arthritis patients with foot complaints: the role of plantar pressure and gait characteristics. Rheumatology (Oxford). 2006, 45:465-9. 10.1093/rheumatology/kei186

25. Michelson J, Easley M, Wigley FM, Hellmann D: Foot and ankle problems in rheumatoid arthritis . Foot Ankle Int. 1994, 15:608-13. 10.1177/107110079401501106

26. Carter K, Lahiri M, Cheung PP, Santosa A, Rome K: Prevalence of foot problems in people with inflammatory arthritis in Singapore. J Foot Ankle Res. 2016, 9:37. 10.1186/s13047-016-0169-y 